\title{
Hydrobiologia
}

\section{Staining of subfossil chironomid head capsules: a method for improving the extraction process from lake sediments and peat \\ --Manuscript Draft--}

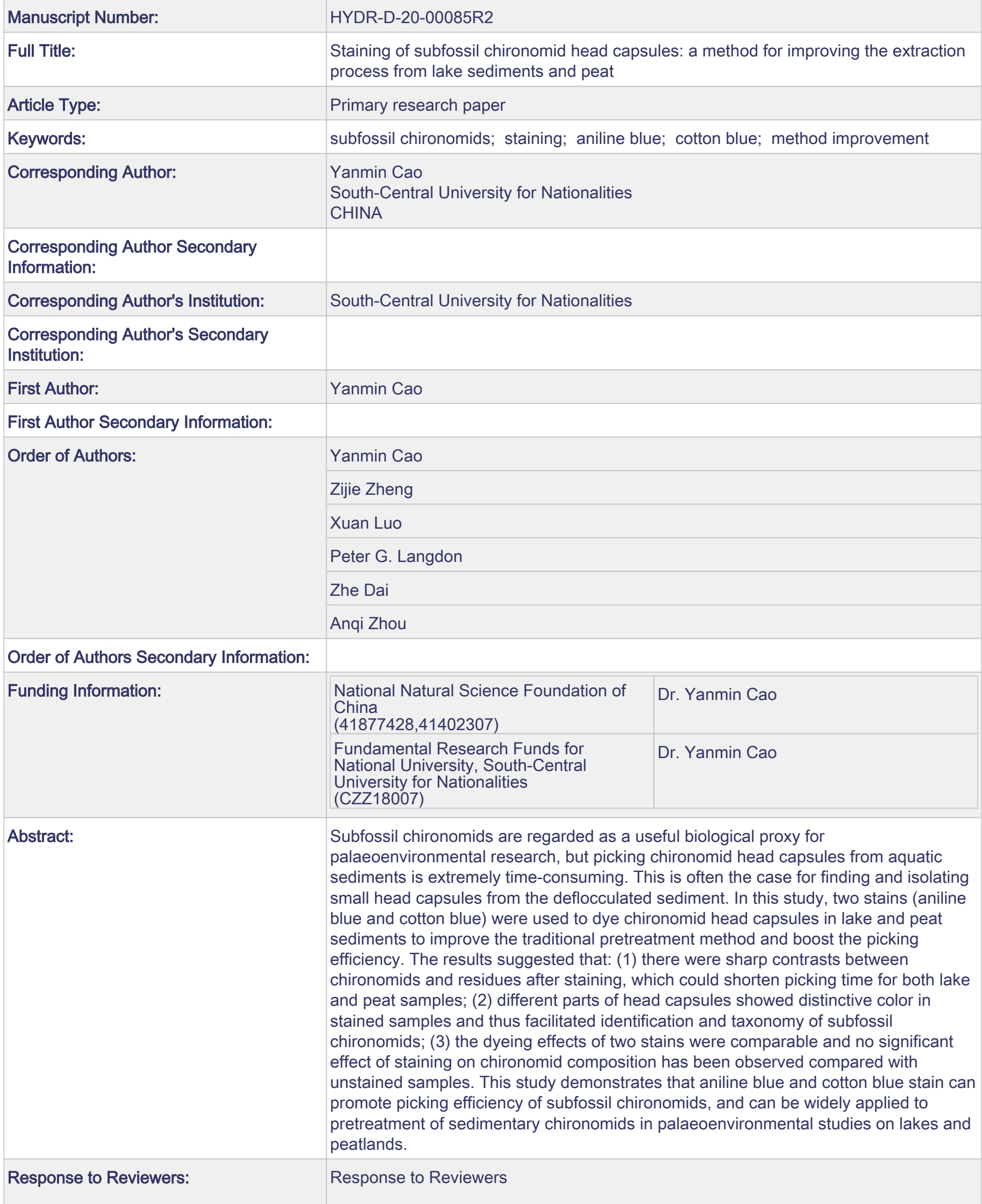


Comments by Editor:

1. According to our Instructions for Authors (Categories of Contributions - available athttps://www.springer.com/journal/10750/submission-

guidelines?IFA\#Instructions\%20for\%20Authors_Categories\%20of\%20Contributions),

"Primary Research papers... MUST be organized according to the standard structure of a scientific paper: Introduction, Materials and Methods, Results, Discussion,

Conclusion, Acknowledgements, References, Tables, Figure captions." In your manuscript results and discussion are presented in a single chapter and this is not acceptable in Hydrobiologia. Please restyle your manuscript in order to keep Results logically separated from Discussion.

Reply: Many thanks to the editor. We have separated Discussion from Results and made them to be single chapters.

2. Moreover, please carefully consider whether all the figures are necessary to illustrate your results (perhaps you can make a selection among the first 4 figures) and eventually move some of them to supplementary materials.

Reply: We have moved figure 2 and 3 in the initial version to supplementray materials and coded them as Supplementary Fig. 1 and 2. We have also adjusted the order of figures in the text according to the revised text. 
1 Staining of subfossil chironomid head capsules: a method for improving the extraction process

\section{2 from lake sediments and peat}

3

$4{\text { Yanmin } \mathrm{Cao}^{1 *} \text {, Zijie Zheng }}^{1,2}$, Xuan Luo $^{1,3}$, Peter G. Langdon ${ }^{4}$, Zhe Dai ${ }^{1}$, Anqi Zhou ${ }^{1}$

5

61 College of Resources and Environmental Science, South-Central University for Nationalities, Wuhan, 7 430074, China

82 State Key Laboratory of Environment Simulation, School of Environment, Beijing Normal 9 University, Beijing, 100875, China

103 Guangzhou Institute of Energy Conversion, Chinese Academy of Sciences, Guangzhou, 510640, 11 China

124 School of Geography and Environmental Science, University of Southampton, Southampton, 13 SO171BJ, UK 


\section{Abstract}

Subfossil chironomids are regarded as a useful biological proxy for palaeoenvironmental research, but picking chironomid head capsules from aquatic sediments is extremely time-consuming. This is often the case for finding and isolating small head capsules from the deflocculated sediment. In this study, two stains (aniline blue and cotton blue) were used to dye chironomid head capsules in lake and peat sediments to improve the traditional pretreatment method and boost the picking efficiency. The results suggested that: (1) there were sharp contrasts between chironomids and residues after staining, which could shorten picking time for both lake and peat samples; (2) different parts of head capsules showed distinctive color in stained samples and thus facilitated identification and taxonomy of subfossil chironomids; (3) the dyeing effects of two stains were comparable and no significant effect of staining on chironomid composition has been observed compared with unstained samples. This study demonstrates that aniline blue and cotton blue stain can promote picking efficiency of subfossil chironomids, and can be widely applied to pretreatment of sedimentary chironomids in palaeoenvironmental studies on lakes and peatlands.

Keywords: subfossil chironomids; staining; aniline blue; cotton blue; method improvement 


\section{Introduction}

Since first reported by Ekman (1915), chironomid head capsules in sediments have been used in palaeoclimatic and palaeoenvironmental reconstructions during the past century across all continents. They were originally employed to qualitatively reconstruct limnological environmental changes, and then were used quantitatively based on the establishment of datasets between chironomid and environmental parameters such as air temperature (e.g. Heiri et al., 2012; Zhang et al., 2017), salinity (e.g. Eggermont et al., 2006; Heinrichs et al., 1999), nutrient levels (e.g. Brooks et al., 2001; Zhang et al., 2012), macrophytes (e.g. Langdon et al., 2010), hypolimnetic dissolved oxygen (e.g. Quinlan \& Smol, 2001a; Luoto \& Salonen, 2010) and water depth (e.g. Kurek \& Cwynar, 2009; Walker et al., 2006).

Chironomid stratigraphies are developed by extracting head capsules from sediments, which needs to be manually sorted individually before being mounted on microscope slides. A variety of extraction techniques exist, depending on the nature of the sediments (summarized in Brooks et al. 2007). The pre-treatment process of one sample generally takes 4-8 hours even for a skilled technician, depending on the sediment type and materials remaining post sediment deflocculation. Researchers have tried various methods to shorten the processing time and improve efficiency of sample pre-treatment. A floatation method was initially used in preparation of other biological indicators, e.g. Coleoptera. Ruiz et al. (2006) first introduced a paraffin floatation method into subfossil chironomid analysis. Subsequently, Rolland \& Larocque (2007) used kerosene floatation to extract chironomid head capsules and proved that this was an effective method with mean extraction efficiency around $89 \%$. But it is not suitable for large head capsules which are often filled with sediments. In the same year, Verschuren \& Eggermont (2007) found that using a large mesh size (e.g. >150 $\mu \mathrm{m}$ ) could effectively reduce sample processing time and had little influence on palaeoecological interpretation. This might be useful for large head capsules from lake sediments in the tropics such as Africa but would fail to be efficient for the processing of small chironomid head capsules which are often numerous in high latitudes and cold water lakes. In order to skip the process of extraction, Velle \& Larocque (2008) found that adding exotic markers (microspheres) to sub-samples was an effective and rapid method to estimate representative concentrations of chironomids in sediments. This method, however, was not conducive to the identification and palaeoecological analysis of chironomids. In 2011, Larocque-Tobler \& Oberli (2011) proposed that the usage of cotton blue stain could improve the efficiency of extraction and identification of chironomid head capsules. They demonstrated that cotton blue could greatly increase the visibility of chironomids and thus make the picking twice as fast (the time needed to pick head capsules from lake sediment samples was reduced from $4-8 \mathrm{~h}$ to $2-4 \mathrm{~h}$ when the samples were stained). It is undoubtedly a good method for both concentration calculation and identification of chironomids. However, it is not clear whether this method is suitable or not for sediment samples from other wetland environments such as peatlands.

Chironomids are often abundant in peatland sediments and have the potential to be a biological proxy to reconstruct the past environmental changes in peatlands (Cao et al., 2019). However, peat samples tend to have numerous residues such as plant fragments (mosses and other vegetation) and other insect shells even after lengthy washing. The picking of head capsules is tedious and can take 2-3 times longer than that for lake sediment samples (Cao, personal observation). Moreover, some individual head capsules hidden in entangled plant debris are more likely to be missed. To test whether cotton blue is equally effective on peat samples, here we compared its dyeing effect on both peat samples and lake sediment samples. Additionally, aniline blue is an excellent stain which has been 
widely used in textile dyeing and biological stains such as recent crustacean zooplankton (Seepersad \& Crippen, 1978; Bickel et al., 2009; Navada \& Kulal, 2019). In this study, we also tested if it is effective for identifying chironomid head capsules from the sediment/plant residue matrix and compared the dyeing effect with that of cotton blue in order to compare the effectiveness and efficiency of different dyeing methods.

\section{Material and methods}

\subsection{Preparation of stains}

Two stains (1\% aniline blue-lactophenol oil reagent and $1 \%$ cotton blue-lactophenol oil reagent) were prepared. Phenol, lactic acid, glycerin and distilled water were configured in an approximately ratio of 1:1:2:1. And then aniline blue or cotton blue was added to form $1 \%$ aniline blue-lactophenol oil (named "aniline blue" thereafter) or $1 \%$ cotton blue-lactophenol oil reagent (named "cotton blue" thereafter). After thoroughly mixed, the stains then could be used to dye samples.

\subsection{Sample collection and experimental treatment}

14 samples including 10 lake sediments (labeled as L1 to L10) and 4 peat samples were analyzed. All sampling sites were situated in Hubei Province (central China). Lake sediments were sampled from floodplain shallow lakes in three adjacent university campuses in Wuhan City, which is the capital of Hubei Province. The sampling was conducted in November 2015, November 2018 and March 2019, respectively. A 1/32 $\mathrm{m}^{2}$ Ekman grab was used and surface $(0-1 \mathrm{~cm})$ sediments were retrieved in field. Peat samples came from Dajiuhu Peatland, which is a subalpine wetland located in western Hubei Province and the elevation over $1760 \mathrm{~m}$ a.s.l.. Four samples were taken, including 2 surface (labeled as D1 and D2 and sampled in the same peat patch) and 2 peat core samples (labeled as Y35 and Y49 from another peat patch), which were sampled in July 2014 and September 2016, respectively. Sediments from lakes or peats were highly homogenized. Many plant macro-remains were observed in peat samples, while lake sediments comprised soft lake mud with few plant residues. All these samples were sealed in plastic bags immediately after collection and stored in refrigerate at $4{ }^{\circ} \mathrm{C}$ until chironomid analyses were undertaken. Properties of sediments and other information of samples are shown in Supplementary Table 1.

For each sample, three experimental groups (Aniline blue, Cotton blue and Unstained) were set. Three replicates of subsamples with equivalent weight were taken, and each was put into a separate 50 $\mathrm{ml}$ beaker which was numbered as 1, 2 and 3 respectively. Subsamples in three groups were initially processed according to the standard techniques proposed by Brooks et al. (2007). Subsamples were deflocculated with $10 \% \mathrm{KOH}$ in a water bath at $75{ }^{\circ} \mathrm{C}$ for $15 \mathrm{~min}$, and then sieved on a $90 \mu \mathrm{m}$ mesh. The residue of No. 1 and 2 was returned to the numbered clean beaker to be stained, while No. 3 was transferred into a glass bottle for chironomid analyses. Beakers numbered 1 and 2 were then given an appropriate amount (all sediments could be completely submerged by the dye) of prepared aniline blue and cotton blue reagent respectively. Sediments were stained at room temperature for about $2 \mathrm{~h}$ and then washed and sieved through a $90 \mu \mathrm{m}$ sieve mesh. The residue of three sub-samples was finally transferred into a grooved Perspex sorting tray for extraction of head capsules.

\subsection{Chironomid extraction and identification}

Chironomid head capsules were preserved well in all sediments. They were examined and sorted manually under a stereo-zoom microscope at $\times 25$ magnification with fine forceps. Head capsules were 
permanently mounted on slides using Hydromatrix ${ }^{\circledR}$ and subsequently identified at $\times 100-400$ magnification using the taxonomy of Brooks et al. (2007), with reference to Epler (2001), Rieradevall \& Brooks (2001) and Tang (2006).

\subsection{Numerical analyses}

Comparisons were made between subsamples with different treatments in head capsule density, species richness and Shannon-Wiener diversity using one-way Analysis of Variance (one-way ANOVA), which was performed in SPSS 25. Species richness was estimated as the raw number of chironomid taxa restored in samples. Shannon-Wiener index was employed to assess chironomid diversity (Shannon \& Weaver, 1963). Species richness and Shannon-Wiener index were calculated in PAST 2.03 (Hammer et al., 2001). Chironomid composition was assessed by relative abundance (\%) of each taxon in all taxa encountered in each subsample. Percentages of taxa are represented in a stratigraphic diagram and only taxa that occurred in at least two samples with a relative abundance of exceeding $2 \%$ in one sample are shown here.

To detect chironomid compositional variance among subsamples with different treatments, a principal component analysis (PCA) based on square-root transformed chironomid taxa was conducted using the program Canoco 5.0 (ter Braak \& Šmilauer, 2012).

\section{Results}

3.1 Color and picking time of sediments

In samples treated by aniline blue, chironomid head capsules were light blue to blue (Fig. 1c and d), but other residues were very light blue or not colored. Most chironomids in cotton-blue stained samples were uniformly colored with bright blue (especially in lake samples, Fig. 1e) or purple (in peat samples, Fig. 1f), although some specimens (relatively small ones) were lightly colored. During the extraction of head capsules, we recorded the picking time for several but not all 10 lake samples (Supplementary Table 2). The time spent on aniline blue, cotton blue and unstained lake samples ranged from 80 130, 70 120 and 90 150 minutes, with average of 103, 133 and 127 minutes, respectively.

\subsection{Chironomid compositional traits}

Head capsule concentrations in 10 lake samples with three treatments ranged from 1.9 to 22.1 ind./g wet sediment, while from 16.1 to 32.5 ind./g wet peat for 4 peat samples. Species richness and Shannon-Wiener diversity index in 10 lake samples varied from 7 to 24 and 1.3 to 2.3 respectively, while from 5 to 15 and 1.0 to 2.4 for peat samples (Fig. 2). High correlations between cotton blue stained and unstained sample assemblages were detected in chironomid compositional traits ( $\mathrm{r}>0.88, p$ $<0.001$ ), while weak correlations existed between aniline blue stained and unstained sample assemblages in taxa number and species diversity $(\mathrm{r}=0.5, p>0.05)$. However, no significant differences $(p>0.05)$ were detected among aniline blue stained, cotton blue stained and unstained samples in these compositional traits as shown by one-way ANOVA.

Figure 3a showed that the percentages of most taxa in aniline blue stained and unstained samples were broadly distributed along the 1:1 line, except for Cricotopus sylvestris-type, Glyptotendipes pallens-type and Microtendipes pedellus-type which fell outside the $10 \%$ deviation range. Only one taxon (Glyptotendipes pallens-type) plotted outside the $10 \%$ deviation range when compared between cotton blue stained and unstained samples (Fig. 3b), and all the other taxa were within 5\% deviation.

PCA analyses of the lake samples (Fig. 4a) showed the first two axes explained $50 \%$ of the 
variance in chironomid assemblages, with the first axis of $33.1 \%$ and the second axis of $16.9 \%$. Subsamples of L7, L8 and L9 clustered and other samples scattered randomly. The PCA of the peat samples (Fig. 4b) captured $50.1 \%$ and $28.0 \%$ of the total variance in chironomids in the first two axes. Three subsamples of one sample clustered together and marked distances between different samples were observed.

\section{Discussion}

4.1 Staining effect of samples

The plates shown in Figure 1 highlight that it was difficult to quickly distinguish subfossil chironomids from other residues as they had a similar color in unstained samples (Fig. 1a and b), which increased the difficulty in head capsule extraction. But strong contrasts between chironomids and the background color were observed in aniline blue and cotton blue stained samples alike, making head capsules clearly visible under stereoscopic microscope. However, the data (Supplementary Table 2) showed that the time spent on stained lake sediments was only about 30 minutes shorter than on unstained sediments for each sample in general. This differs from other available report such as Larocque-Tobler and Oberli (2011), as they concluded that 50\% (1-2 h) reduction of the picking time spent on cotton blue samples compared with unstained sediments. In total, we checked the sediments 2-3 times for stained and unstained samples alike to ensure that all head capsules in samples are picked out. We found that some valid head capsules (half or whole head capsules which would be counted in palaeoecology) could still be observed during the second even third check in unstained samples while only invalid remains (less than half head capsules) existed in stained samples. This revealed that checking the stained samples only once is enough to sort out all head capsules for a moderate-skilled technician. This will save more time than the timing data provided here.

Peat samples typically contain relatively more plant remains than lake sediment samples (although this will vary with lake type and sample location, as littoral samples and/or shallow lake samples may be plant rich), which take longer to sort through, often up to 7-8 h in general (Cao, personal observation). The tedious picking process was inevitably interrupted and often failed to be done continuously. As such the total picking time for each peat sample was not recorded in this study. Nevertheless, similar to lake samples, the head capsules from the stained samples could be picked in one go, whereas this was not the case for unstained peat samples. It should be noted that, stained samples were washed twice but only once for unstained samples during the washing process. Although the long rinsing time cleaned each control sample sufficiently, the double washing for stained samples might have potential effects on the picking of head capsules, for example, through helping deflocculate the sediment further. Nonetheless we concluded that the picking time was shortened and the picking efficiency was promoted through staining for both lake and peat samples.

Under the microscope at x100-400 magnification, different parts of the head capsules had sharp contrast both in the aniline blue stained and cotton blue stained samples (Fig. 5 and Supplementary Fig. 1 and 2). The mentum, mandible and outer edge of head capsules were still colored brown or black, while head capsules were blue or purple (Fig. 5 and Supplementary Fig. 1 and 2). Striations, the anterior margin on ventromental plates and cephalic setation (ventral) in Tanypodinae became more visible in stained samples (Fig. 5c, h), and hence were easier to be identified. This could boost the efficiency of identification, and may facilitate the improvement of identification level in future work.

\subsection{Comparison of chironomid compositional traits between stained and unstained samples}


In all 14 samples with aniline blue staining, 8 had higher head capsule density than that in unstained samples, while 7 samples had higher or equivalent values in species richness and diversity index as that of unstained samples (Fig. 2a). This might indicate that aniline blue staining would enable less head capsules and specimens embedded by plant detritus or residuals to be neglected. Aniline blue performed better than cotton blue staining in these compositional traits, as most cotton blue stained samples were found to have lower species richness and diversity compared with unstained samples (Fig. $2 b)$.

Most taxa had similar relative abundance in three equivalents for each sample as shown in Fig. 6. This was especially the case for cotton blue staining, as only one taxon fell outside the $10 \%$ deviation range of 1:1 line in species abundance (Fig. 3b). This suggested similar community composition before and after staining by cotton blue. Taxa which occurred in one subsample but not in other ones for each sample often had low abundance percentages, typically $<2 \%$. Such low abundance, i.e. the rare taxa, are often not interpreted in palaeoecological reconstructions. Nonetheless, rare taxa with narrow ecological tolerances can exert significant effects on transfer functions depending on the selected model type. Moreover, it can often be the rare taxa that convey important information about ecosystem resilience and structure (Doncaster et al., 2016; Wang et al., 2019) and hence ensuring rare taxa are well identified should be an important palaeoecological tenet.

PCA biplots (Fig. 4) revealed that chironomid composition were distinct among different peat samples while similar within each sample between stained and unstained treatment. However, the distance among most different samples from lakes are not so remarkable in this study except for three samples L7, L8 and L9, which had the total sum of sorted head capsules exceeding 100. To some extent, fewer peat samples than lake samples contributed to their longer distance (greater variability) among different sampling sites in the PCA plot. In addition, complex microtopography (hummocks and hollows) and high heterogeneity is more likely to weaken spatial autocorrelation of biotic communities in peatlands (Cao et al., 2019), which helps explain the closer distribution of different lake samples in the PCA biplot. Generally, as more individuals are counted more rare taxa are typically found until an equilibrium is reached. Three lake samples producing the most head capsules also had the most rare taxa types (average of 9.6 rare types per sample compared with others of 0-7 rare taxa) and highest species richness (11-24 while other samples ranged from 7 to 16). Available reports have shown that 50 head capsules can work well for statistical treatments (transfer functions) and should be treated as a standard criterion during palaeoclimatic and palaeolimonological reconstruction (Heiri \& Lotter, 2001; Quinlan \& Smol, 2001b). However, for some palaeoecological studies, especially where the influence of rare types is important, serious bias may occur when using 50 head capsules in reconstruction, hence researchers are encouraged to experiment with each new site to test how many individuals should be counted until the diversity does not increase significantly.

\section{Conclusions}

Our study compared the picking efficiency and chironomid composition among samples with different pretreatment. The results suggested that: (1) staining can promote the extraction efficiency of head capsules as the picking time could be shortened for both lake and peat sediment samples; (2) after staining by aniline blue and cotton blue, different parts of head capsules had greater contrast which facilitated chironomid identification and taxonomy; (3) the dyeing effects of two stains were comparable and no significant divergence was observed in head capsule concentration and chironomid compositions in aniline blue and cotton blue stained samples from unstained samples. These results 
suggest that staining should not pose a negative impact on the interpretation of past environmental information.

\section{Acknowledgement}

We are very grateful to the editors and two anonymous reviewers for their useful comments and suggestions. This study was supported by the National Natural Science Foundation of China (Grant Number: 41877428; 41402307) and the Fundamental Research Funds for National University, South-Central University for Nationalities (Grant Number: CZZ18007).

\section{References}

Bickel, S. L., K. W. Tang \& H. P. Grossart, 2009. Use of aniline blue to distinguish live and dead crustacean zooplankton composition in freshwaters. 54: 971-981.

Brooks, S. J., H. Bennion \& H. J. B. Birks, 2001. Tracing lake trophic history with a chironomid-total phosphorus inference model. Freshwater Biology 46: 513-533.

Brooks, S. J., P. Langdon \& O. Heiri, 2007. The identification and use of palaearctic Chironomidae larvae in palaeoecology. Quaternary Research Association Technical Guide 10, London: 1-276.

Cao, Y., P. G. Langdon, Y. Yan, S. Wang, Z. Zheng \& Z. Zhang, 2019. Chironomid communities from subalpine peatlands in subtropical China as indicators of environmental change. Journal of Paleolimnology 62: 165-179.

Doncaster, C. P., V. A. Chávez, C. Viguier, R. Wang, E. Zhang, X. Dong, J. A. Dearing, P. G. Langdon \& J. G. Dyke, 2016. Early warning of critical transitions in biodiversity from compositional disorder. Ecology 97: 3079-3090.

Eggermont, H., O. Heiri \& D. Verschuren, 2006. Fossil Chironomidae (Insecta : Diptera) as quantitative indicators of past salinity in African lakes. Quaternary Science Reviews 25: 1966-1994.

Ekman, S., 1915. Die Bodenfauna des Vättern, qualitativ und quantitativ untersucht. Internationale revue der gesamten Hydrobiologie und Hydrographie 7: 146-204, 275-425.

Epler, J. H., 2001. Identification manual for the larval Chironomidae (Diptera) of North and South Carolina. North Carolina Department of Environment and Natural Resources, Division of Water Quality.

Hammer, Ø., D. Harper \& P. Ryan, 2001. PAST: Paleontological statistics software package for education and data analysis. Palaeontologica Electronica 4: 1-9.

Heinrichs, M. L., I. R. Walker, R. W. Mathewes \& R. J. Hebda, 1999. Holocene chironomid-inferred salinity and paleovegetation reconstruction from Kilpoola Lake, British Columbia. Géographie Physique et Quaternaire 53: 211-221.

Heiri, O., S. J. Brooks, H. J. B. Birks \& A. E. Lotter, 2012. A 274-lake calibration data-set and inference model for chironomid-based summer air temperature reconstruction in Europe. Quaternary Science Reviews 30: 3445-3456.

Heiri, O. \& A. F. Lotter, 2001. Effect of low count sums on quantitative environmental reconstructions: An example using subfossil chironomids. Journal of Paleolimnology 26: 343-350.

Kurek, J. \& L. C. Cwynar, 2009. The potential of site-specific and local chironomid-based inference models for reconstructing past lake levels. Journal of Paleolimnology 42: 37-50.

Langdon, P. G., Z. Ruiz, S. Wynne, C. D. Sayer \& T. A. Davidson, 2010. Ecological influences on 
larval chironomid communities in shallow lakes: implications for palaeolimnological interpretations. Freshwater Biology 55: 531-545.

Larocque-Tobler, I. \& F. Oberli, 2011. The use of cotton blue stain to improve the efficiency of picking and identifying chironomid head capsules. Journal of Paleolimnology 45: 121-125.

Luoto, T. P. \& V. P. Salonen, 2010. Fossil midge larvae (Diptera: Chironomidae) as quantitative indicators of late-winter hypolimnetic oxygen in southern Finland: a calibration model, case studies and potentialities. Boreal Environment Research 15: 1-18.

Navada, K. K. \& A. Kulal, 2019. Enhanced production of laccase from gamma irradiated endophytic fungus: A study on biotransformation kinetics of aniline blue and textile effluent decolourisation. Journal of Environmental Chemical Engineering 8: 103550.

Quinlan, R. \& J. P. Smol, 2001a. Chironomid-based inference models for estimating end-of-summer hypolimnetic oxygen from south-central Ontario shield lakes. Freshwater Biology 46: 1529-1551.

Quinlan, R. \& J. P. Smol, 2001b. Setting minimum head capsule abundance and taxa deletion criteria in chironomid-based inference models. Journal of Paleolimnology 26: 327-342.

Rieradevall, M. \& S. J. Brooks, 2001. An identification guide to subfossil Tanypodinae larvae (Insecta: Diptera: Chironomidae) based on caphalic setation. Journal of Paleolimnology 25: 81-99.

Rolland, N. \& I. Larocque, 2007. The efficiency of kerosene flotation for extraction of chironomid head capsules from lake sediments samples. Journal of Paleolimnology 37: 565-572.

Ruiz, Z., A. G. Brown \& P. G. Langdon, 2006. The potential of chironomid (Insecta: Diptera) larvae in archaeological investigations of floodplain and lake settlements. Journal of Archaeological Science 33: 14-33.

Seepersad, B. \& R. W. Crippen, 1978. Use of aniline blue for distinguishing between live and dead freshwater zooplankton. Journal of the Fisheries Research Board of Canada 35: 1363-1366.

Shannon, C. E. \& W. Weaver, 1963. The mathematical theory of communication. University Illinois Press, Urbana.

Tang, H. Q., 2006. Biosystematic study on the chironomid larvae in China (Diptera: Chironomidae). Nankai University, Tianjin, China, $\mathrm{PhD}$ thesis (in Chinese).

ter Braak, C. J. \& P. Šmilauer, 2012. Canoco reference manual and user's guide: software for ordination, version 5.0. Microcomputer power.

Velle, G. \& I. Larocque, 2008. Assessing chironomid head capsule concentrations in sediment using exotic markers. Journal of Paleolimnology 40: 165-177.

Verschuren, D. \& H. Eggermont, 2007. Sieve mesh size and quantitative chironomid paleoclimatology. Journal of Paleolimnology 38: 329-345.

Wang, R., J. A. Dearing, C. P. Doncaster, X. Yang, E. Zhang, P. G. Langdon, H. Yang, X. Dong, Z. Hu, M. Xu, Y. Zhao \& J. Shen, 2019. Network parameters quantify loss of assemblage structure in human-impacted lake ecosystems. Global Change Biology 25: 3871-3882.

Walker, I. R., E. M. Barley, J. Kurek, L. C. Cwynar, R. W. Mathewes, K. Gajewski \& B. P. Finney, 2006. A northwest North American training set: distribution of freshwater midges in relation to air temperature and lake depth. Journal of Paleolimnology 36: 295-314.

Zhang, E., Y. Cao, P. Langdon, R. Jones, X. Yang \& J. Shen, 2012. Alternate trajectories in historic trophic change from two lakes in the same catchment, Huayang Basin, middle reach of Yangtze River, China. Journal of Paleolimnology 48: 367-381.

Zhang, E., J. Chang, Y. Cao, H. Tang, P. Langdon, J. Shulmeister, R. Wang, X. Yang \& J. Shen, 2017. A chironomid-based mean July temperature inference model from the south-east margin of the 
Tibetan Plateau, China. Climate of the Past 13: 185-199.

342 
344 Fig.1 Comparisons of unstained ( $a$ and b), aniline blue stained ( $c$ and d) and cotton blue stained (e 345 and f) samples. Pictures of a, c and e are lake samples, while b, d and f are peat samples. 346 Chironomid head capsules are marked using squares. All images were taken at the same 347 magnification $(\times 400)$ without any post-processing.

348 Fig.2 Comparisons of chironomid compositional traits between (a) aniline blue stained, (b) cotton 349 blue stained and unstained samples. Black circles are lake sediment samples and red circles are 350 peat samples.

351 Fig.3 Comparison of percentage of taxa found in (a) aniline blue stained and (b) cotton blue 352 stained and unstained samples from lakes (black circles) and peatlands (red circles). The solid line 353 represents a 1:1 relationship in taxa abundance between stained and unstained sample. The short 354 dotted and long dotted lines indicate the 5\% and 10\% bias compared to the 1:1 line. The taxa with 355 bias exceeding $10 \%$ and the sample (in parenthesis) are marked.

356 Fig.4 PCA biplot showing the similarity between subsamples with different treatments for (a) 357 lakes and (b) peatlands. Three lake samples (L7, L8 and L9) with shortest distance among 358 subsamples in (a) and each sample with different treatment in (b) were clustered using ellipses.

359 Fig.5 Important parts in identification of different chironomids in stained lake samples (a-d) and 360 peat sample (e-h). The above four pictures are aniline blue stained head capsules: (a) and (b) show 361 the obvious edges of ventromental plates in Glyptotendipes pallens-type and Tanytarsus, (e) displays cephalic setation (ventral) on Paramerina and (f) shows ventromental plate with striations of Polypedilum. The lower four images are cotton blue stained head capsules: (c) and (h) show remarkable cephalic setations (ventral) in Tanypodinae, (d) display the edge of ventromental plates in Glyptotendipes pallens-type, and ( $\mathrm{g}$ ) shows the setae submenti in Limnophyes. All these details were snapshot in $\times 400$ magnification under the same microscope of Nikon Eclipse E200. Fig.6 Chironomid assemblages in each sample from lakes (A) and peatlands (B) with different treatment: aniline blue stained (AB), cotton blue stained (CB) and unstained (UN). 

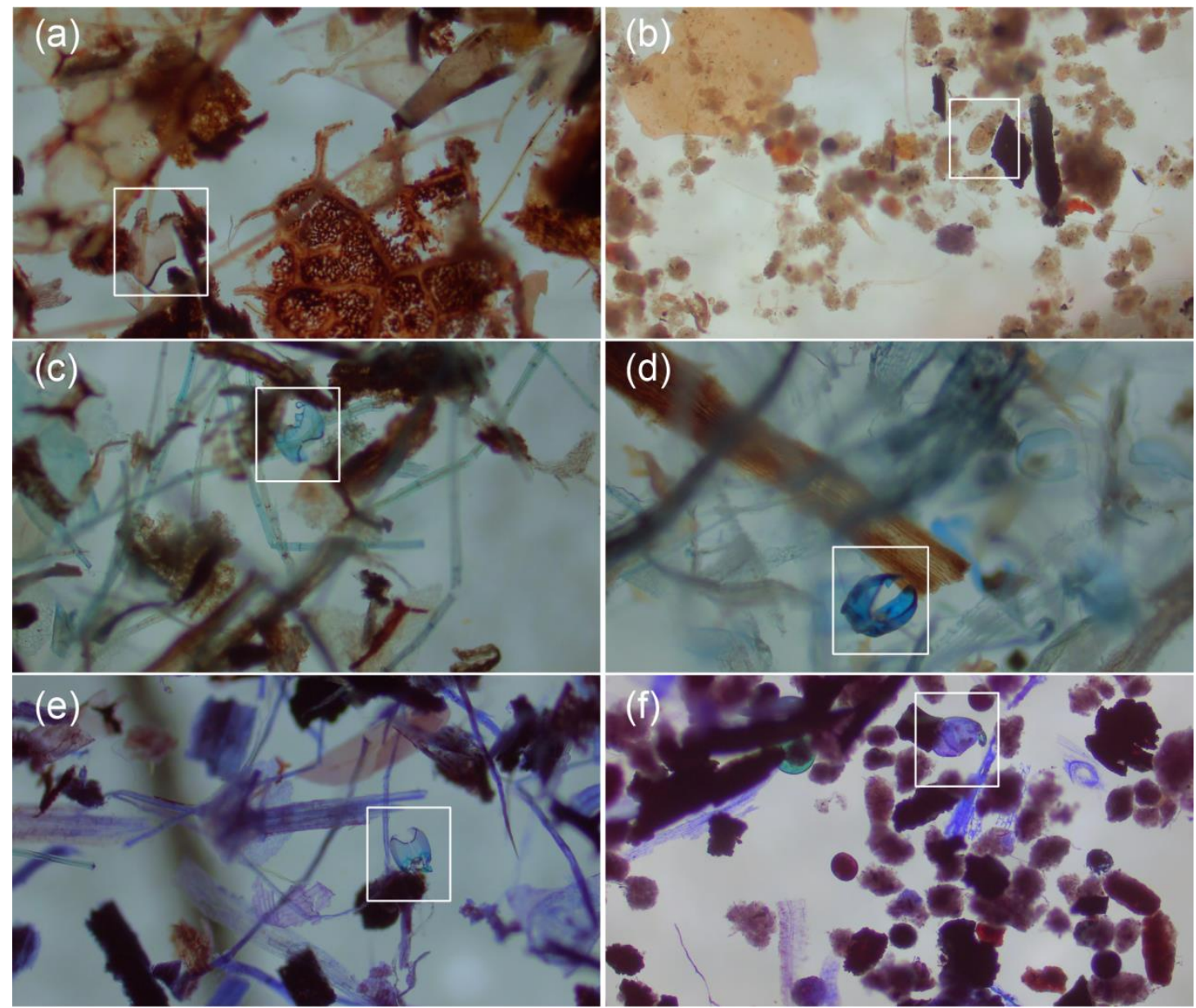

Figure 1 Comparisons of unstained ( $a$ and $b$ ), aniline blue stained ( $c$ and d) and cotton blue stained (e and f) samples. Pictures of a, $c$ and e are lake samples, while b, $d$ and $f$ are peat samples. Chironomid head capsules are marked using squares. All images were taken at the same magnification $(\times 400)$ without any post-processing. 
(a) Aniline blue staining

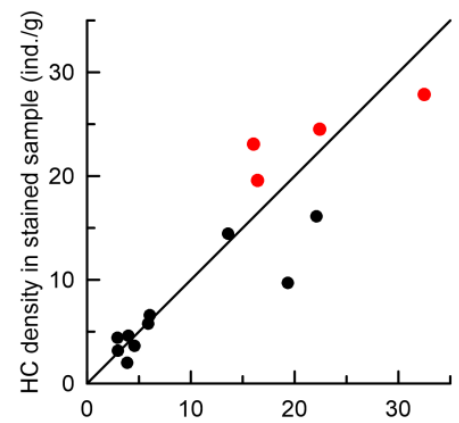

(b) Cotton blue staining

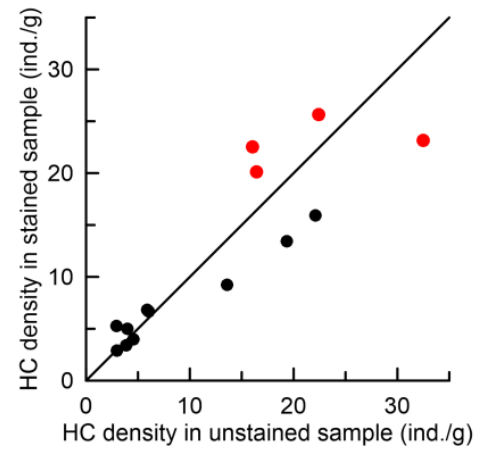

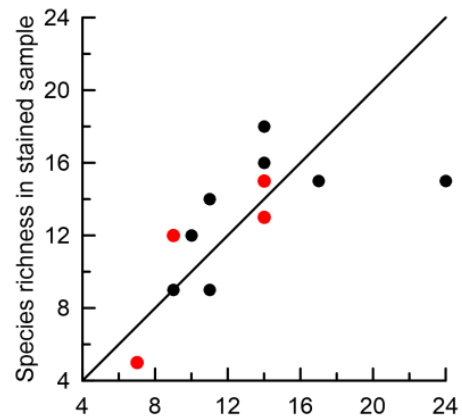
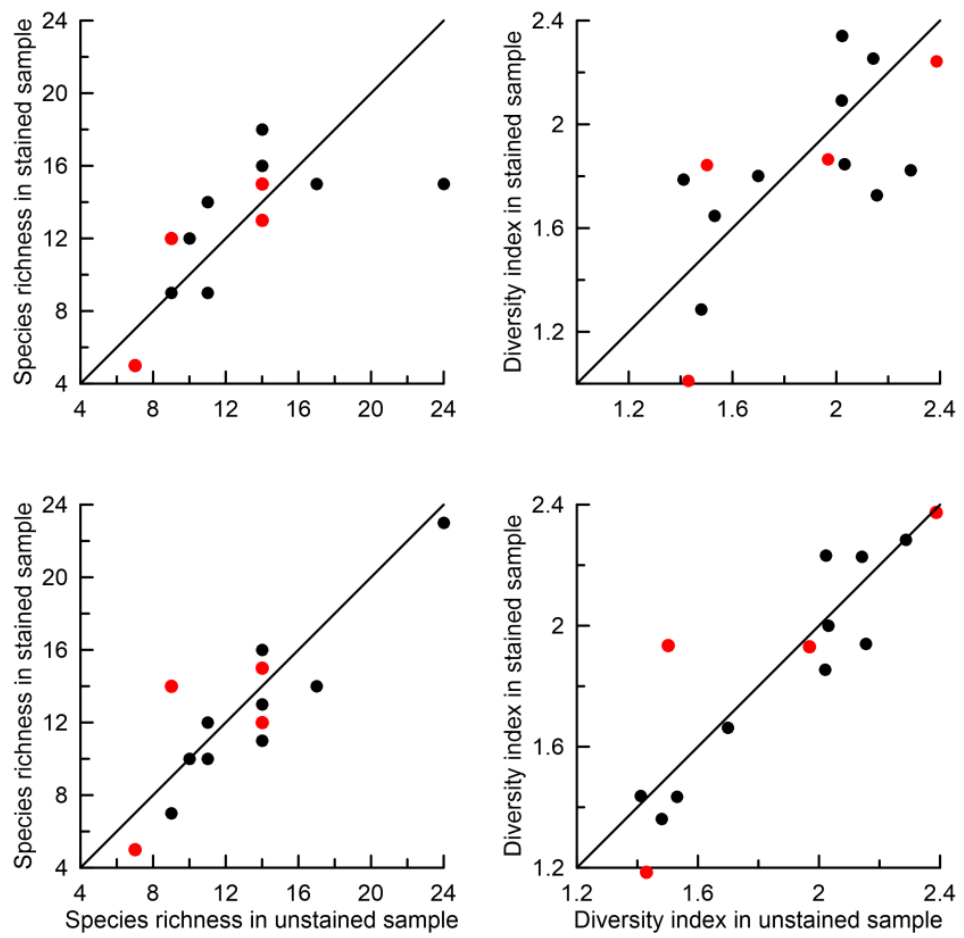

Figure 2 Comparisons of chironomid compositional traits between (a) aniline blue stained, (b) cotton blue stained and unstained samples. Black circles are lake sediment samples and red circles are peat samples. 

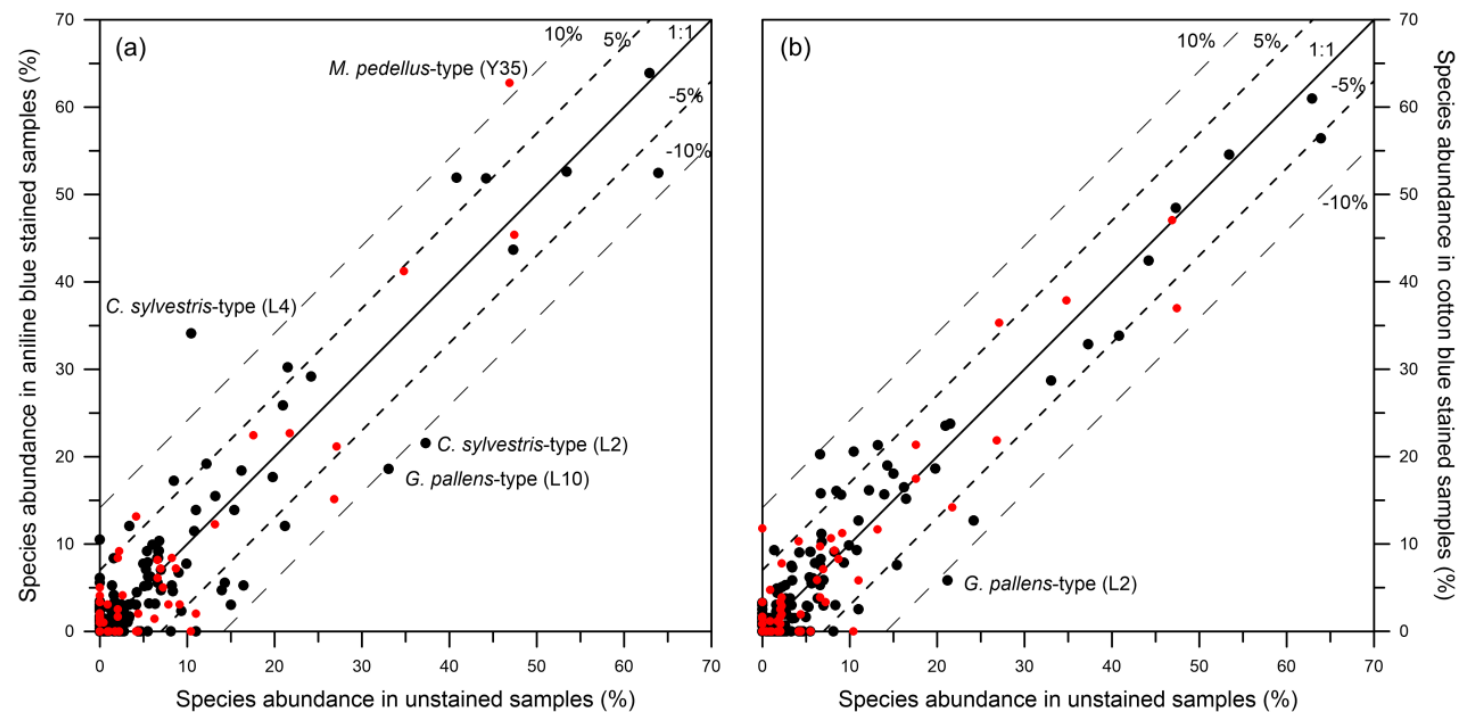

Figure 3 Comparison of percentage of taxa found in (a) aniline blue stained and (b) cotton blue stained and unstained samples from lakes (black circles) and peatlands (red circles). The solid line represents a 1:1 relationship in taxa abundance between stained and unstained sample. The short dotted and long dotted lines indicate the 5\% and 10\% bias compared to the 1:1 line. The taxa with bias exceeding $10 \%$ and the sample (in parenthesis) are marked. 

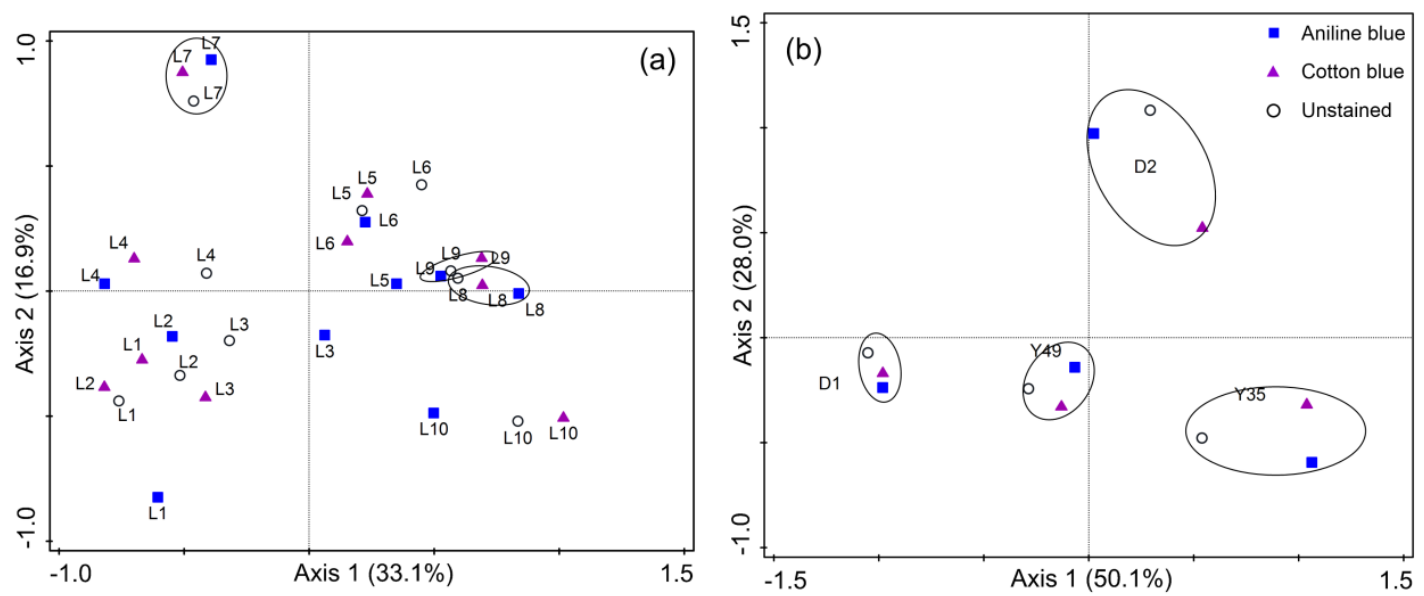

Figure 4 PCA biplot showing the similarity between subsamples with different treatments for (a) lakes and (b) peatlands. Three lake samples (L7, L8 and L9) with shortest distance among subsamples in (a) and each sample with different treatment in (b) were clustered using ellipses. 

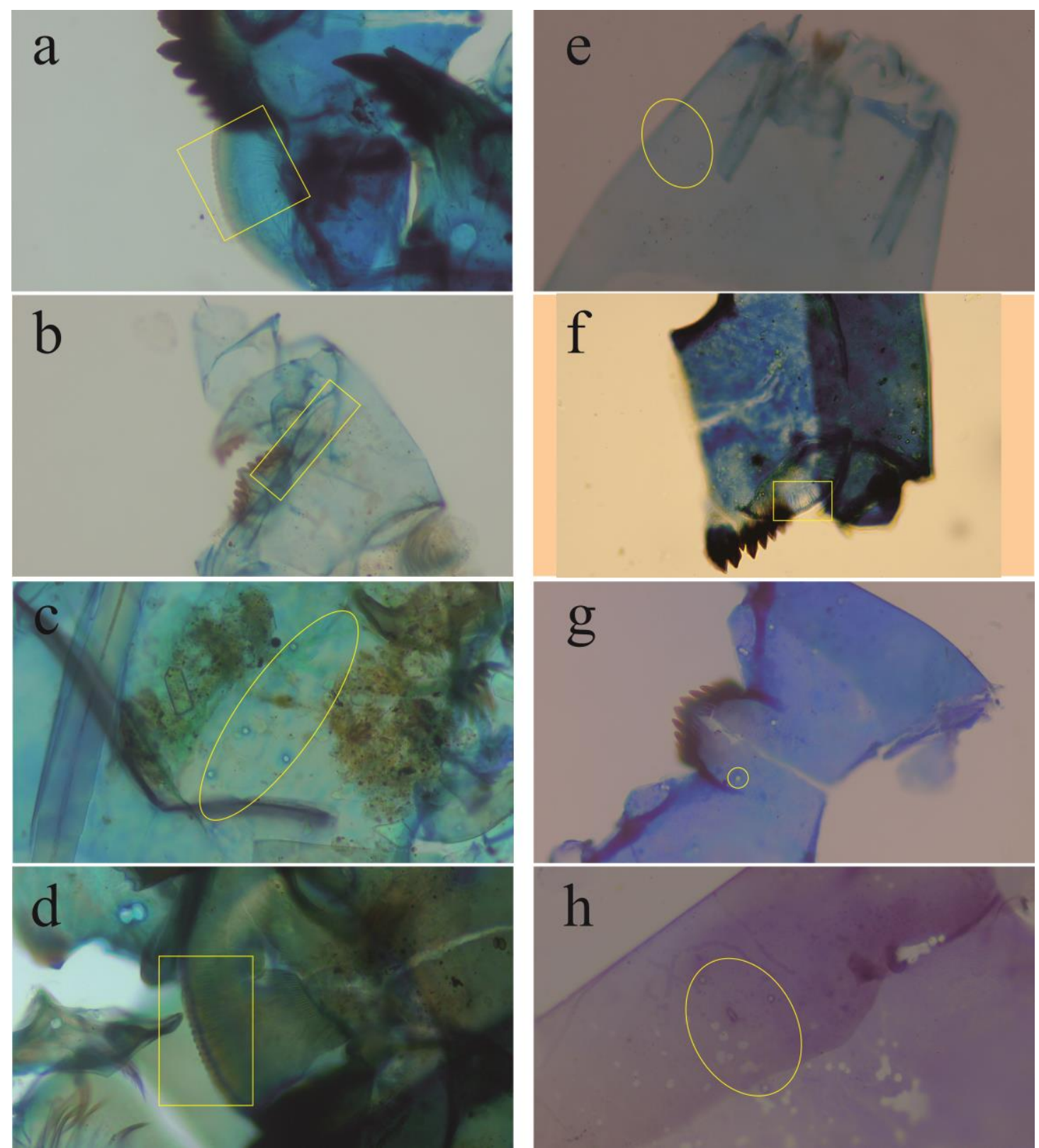

Figure 5 Important parts in identification of different chironomids in stained lake samples (a-d) and peat sample (e-h). The above four pictures are aniline blue stained head capsules: (a) and (b) show the obvious edges of ventromental plates in Glyptotendipes pallens-type and Tanytarsus, (e) displays cephalic setation (ventral) on Paramerina and (f) shows ventromental plate with striations of Polypedilum. The lower four images are cotton blue stained head capsules: (c) and (h) show remarkable cephalic setations (ventral) in Tanypodinae, (d) display the edge of ventromental plates in Glyptotendipes pallens-type, and (g) shows the setae submenti in Limnophyes. All these details were snapshot in $\times 400$ magnification under the same microscope of Nikon Eclipse E200. 

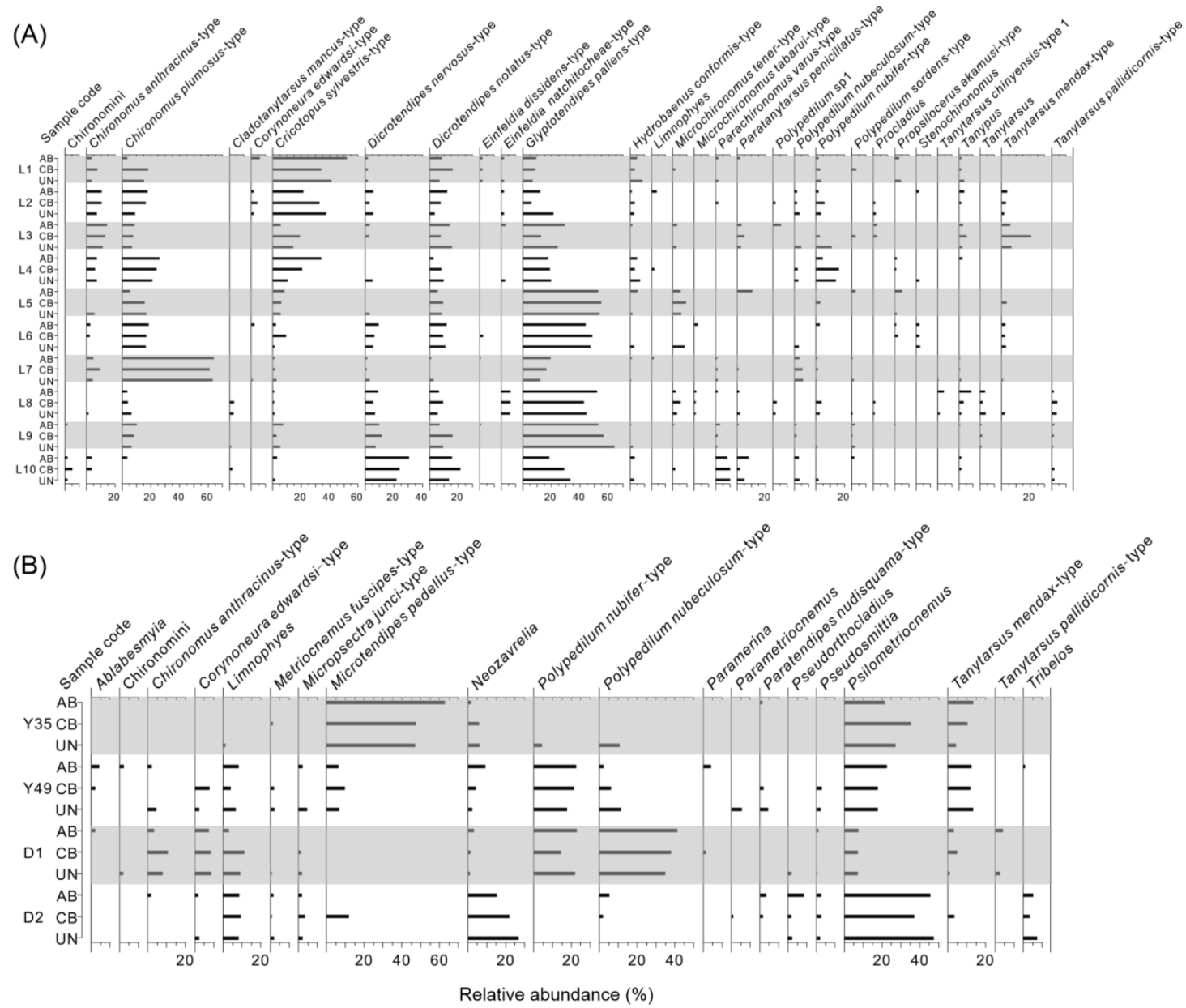

Figure 6 Chironomid assemblages in each sample from lakes (A) and peatlands (B) with different treatment: aniline blue stained $(\mathrm{AB})$, cotton blue stained $(\mathrm{CB})$ and unstained $(\mathrm{UN})$. 
Click here to access/download Supplementary Material Supplementary table 1.docx 
Click here to access/download Supplementary Material Supplementary table 2.docx 
Click here to access/download Supplementary Material Supplementary Figures.docx 